\title{
A Novel Concept for In Situ Gas-Phase Laser Raman Spectroscopy for SOFC
}

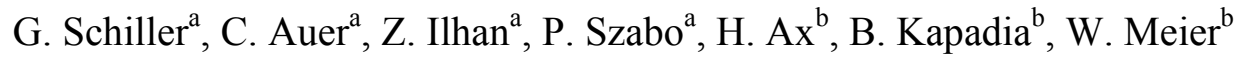 \\ ${ }^{a}$ Institute of Technical Thermodynamics, German Aerospace Center (DLR), D-70569 \\ Stuttgart, Germany \\ ${ }^{\mathrm{b}}$ Institute of Combustion Technology, German Aerospace Center (DLR), D-70569 \\ Stuttgart, Germany
}

\begin{abstract}
Gas-phase laser Raman spectroscopy has recently been adopted to determine the concentrations of relevant gaseous species within the anode flow channel with high spatial and temporal resolution during operation at technically relevant operating conditions. The paper describes the configuration of an optically accessible SOFC, the laser system and optical setup for 1 D Raman spectroscopy as well as the challenges associated with the measurements of an electrolyte supported cell of a size of $50 \times 50 \mathrm{~mm}^{2}$. At different operating conditions Raman spectra were recorded and concentration profiles of gas species along the flow path in the anode were determined demonstrating this new experimental approach for a better understanding of SOFC processes.
\end{abstract}

\section{Introduction}

High electrical performance and long lifetime are key requirements that must be fulfilled for a successful introduction of solid oxide fuel cells into the market. Inhomogeneous distributions of electrochemical and thermal properties such as local power density and local temperature can detrimentally affect both efficiency and long-term durability through thermo-mechanical stress and degradation phenomena induced by locally varying operating conditions (1). The application of advanced diagnostic methods for monitoring cell characteristics of solid oxide fuel cells under real operating conditions can provide detailed information about the spatial distribution of cell properties in order to increase the fundamental understanding and to optimize the operational behavior. To study inhomogeneous cell properties during operation, spatially resolved diagnostic techniques such as segmented cell technology has been developed at DLR that allows for the in situ determination of local current density and voltage, local impedance data, and temperature distribution as well as local gas concentrations $(2,3,4)$. The obtained data can be used for mathematical modeling and model validation and for predicting physical, electrochemical and fluid mechanical properties (5).

To complement the existing diagnostic techniques, advanced laser measurement techniques can be adopted. They allow a spatially and temporally resolved in-situ determination of gas-phase properties such as composition, temperature and flow velocity (6). Solid-state Raman spectroscopy has been applied for studying SOFC processes ex-situ to determine local temperature and map out phase stability of solid electrode surfaces by monitoring the temporal variation of the oxidation state of materials, to analyze water vapor and methane concentrations in a solid oxide fuel cell and to study carbon formation 
and deposition on anode surface as well as sulfur poisoning mechanisms, $\mathrm{CO}$ oxidation and $\mathrm{NiO}$ redox kinetics (7-13). Gas-phase Raman spectroscopy in the flow channel of an SOFC has only recently been reported (14) but the used optically accessible SOFC and Raman setup was quite different from the one described here. First results of in situ measurements of anode gas concentrations measured simultaneously in one dimension along the flow channel are reported.

\section{Challenges in Operating an Optically Accessible SOFC}

A number of challenges are encountered in operating an optically accessible SOFC at about $1123 \mathrm{~K}$ and performing gas-phase Raman spectroscopy in it. Requirement for laserbased techniques is optical access both for the laser beam itself and the laser-induced optical signals. This is not trivial in case of the complex geometry and high operating temperatures $\left(800-1000{ }^{\circ} \mathrm{C}\right)$ of SOFCs, which are usually based on opaque ceramic materials. Therefore, an important step towards the applicability of laser diagnostics lies in the construction of SOFCs with optical access which are able to operate under technically relevant conditions. In the work described here, an optically transparent anode flow field for a planar SOFC cell is applied which allows for the investigation of the concentrations of relevant gaseous species within the anode flow channel. The SOFC and the test rig have been designed for the application of one-dimensional laser Raman spectroscopy. With respect to the SOFC, a construction enabling a leak-tight operation of the cell and coping with fouling of the quartz glass surfaces are issues.

As for the 1D Raman measurement setup, the collimation of a high-power laser beam to a long and narrow beam waist (over $40 \mathrm{~mm}$ length) without damaging the glass or generating an optical breakdown (plasma) presents a trade-off between signal strength and damage. It is also difficult to maintain the alignment of the laser beam during the heat-up phase of the fuel cell setup. Signal background arising from Rayleigh scattering and laser stray light from surfaces must be efficiently reduced by proper beam alignment and optical filters. Another source of signal background is laser-induced luminescence from quartz glass that interferes with the Raman signals. For the conversion of the Raman signals to species mole fractions, calibration measurements are necessary which should be performed under the same optical boundary conditions as the measurements in the operating fuel cell. Great care has to be taken to maintain the boundary conditions (like optical alignment or window transmissivity) during the measurements.

\section{Experimental Details}

\section{$\underline{\text { SOFC Test Station }}$}

A SOFC test station from FuelCon, Magdeburg, Barleben, Germany (Type Evaluator $\mathrm{C} 100-\mathrm{HT}$ ) including a customized furnace with a maximum temperature of $1100{ }^{\circ} \mathrm{C}$ was equipped with ports $\left(10 \times 50 \mathrm{~mm}^{2}\right)$ for the laser beam and a quartz glass window $(150 \mathrm{~mm}$ diameter) for the detection of the Raman signals. A sketch of the experimental arrangement in Fig. 1 illustrates the experimental setup with a view from side and top. 

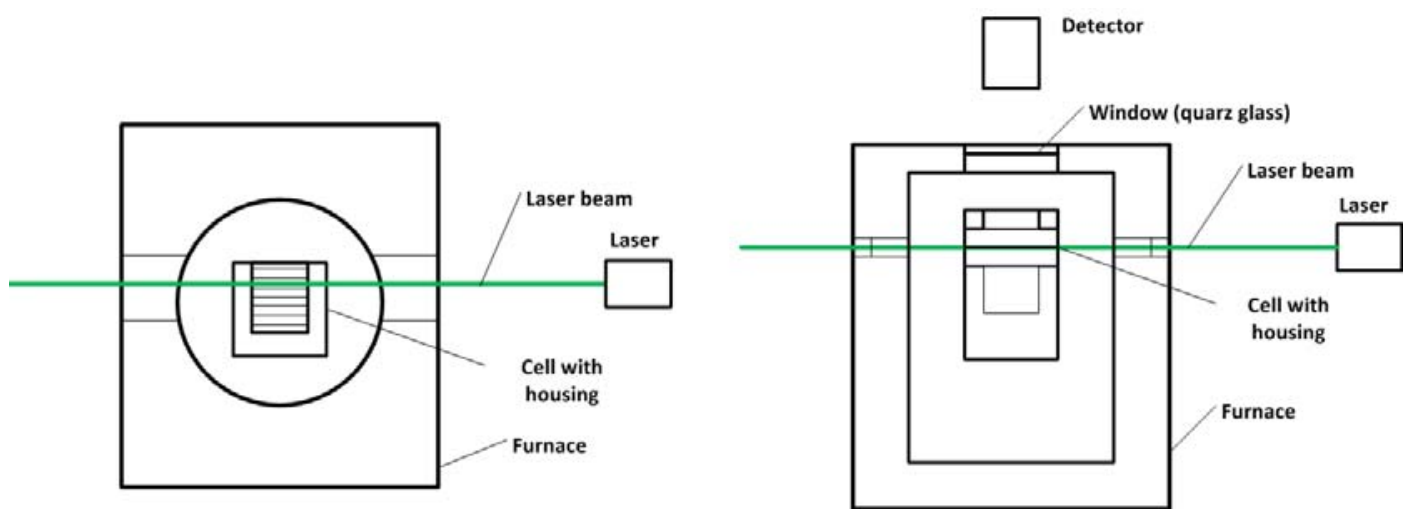

Figure 1. Sketch of the experimental arrangement illustrating the experimental setup: side view (left), top view (right)

Figure 2 shows a photograph of the opened furnace during laser test operation. The furnace confines a cylindrical volume of $300 \mathrm{~mm}$ diameter in which the SOFC cell was placed. For the installation of the cell and laser alignment, the upper part of the furnace can be opened.

The setup for the cell compartment is based on a non-standard ceramic housing. The cell was placed in upright position between an anode (quartz) and a cathode (alumina) flow field in an alumina housing and sealed by gold rings. The pressure for sealing was applied via a ceramic wedge with a weight $(2 \mathrm{~kg})$ on its top. For contacting, platinum nets were used on both the anode and the cathode side. Fig. 3 shows a photograph of the SOFC setup taken through the observation window of the furnace during operation at high temperature. Planar electrolyte-supported cells (ESC) were used for the measurements. Cells with a size of 50 x $50 \mathrm{~mm}^{2}$ were obtained from H.C. Starck Ceramics (Selb, Germany). They consisted of a Ni/GDC anode $(40 \mu \mathrm{m})$, a TZ3Y electrolyte $(100 \mu \mathrm{m})$ and a 8YSZ/LSM-LSM cathode $(40 \mu \mathrm{m})$. ESCs have advantages for this type of test setup since it is possible to seal both gas manifolds with gold rings and the $100 \mu \mathrm{m}$ thick, leak tight electrolyte enables a good electrochemistry.

In order to provide optical access to the anode of the cell the anode flow field was entirely consisting of polished quartz glass (Suprasil 2 grade B) and hence transparent in the spectral range of interest. A cut-out along a gas channel was introduced in the $\mathrm{Pt}$ contact mesh in order to ensure visibility to the anode layer for the Raman spectroscopy. The complex flow field with 9 narrow channels $\left(3 \times 4 \mathrm{~mm}^{2}\right)$ and a length of $40 \mathrm{~mm}$ has been fabricated using a thermal bonding technique for glass material (Hellma, Müllheim, Germany). Fig. 4 shows a photograph of the transparent flow field for the anode. The SOFC cell can be supplied by different fuel gases $\left(\mathrm{H}_{2}, \mathrm{~N}_{2}, \mathrm{H}_{2} \mathrm{O}, \mathrm{CH}_{4}, \mathrm{CO}, \mathrm{CO}_{2}\right)$ and air; a system software (FuelWork) managed all test parameters, provided data logging and controlled a multistage alarm system with sensors for hydrogen and $\mathrm{CO}$. The gases for cell operation were supplied by tubes made of Inconel. 


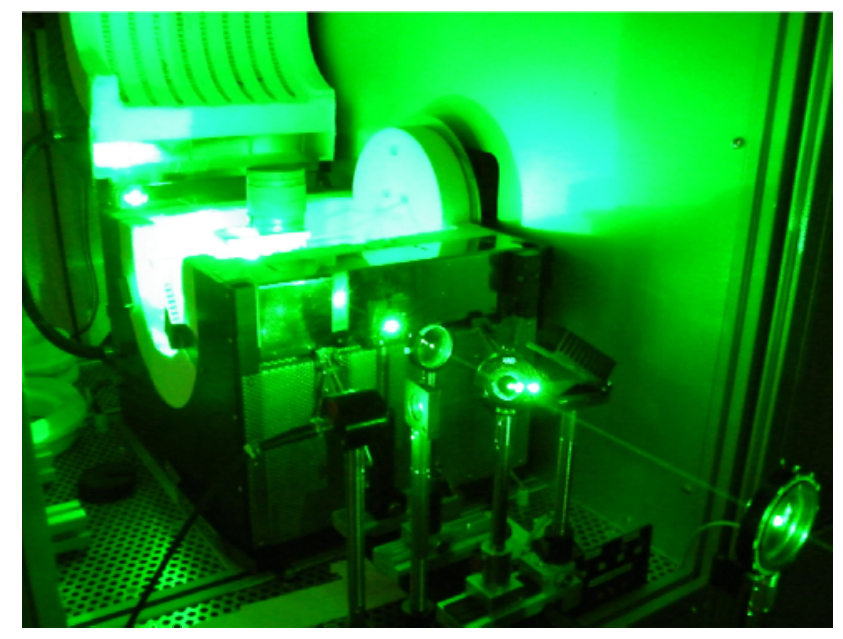

Figure 2. Photograph of the furnace with opened cover and laser beam $(\lambda=532 \mathrm{~nm})$ traveling from the bottom right into the furnace. The Raman scattered light is collected perpendicularly to the laser beam through the opening on the left side. The photo also illustrates the huge amount of laser stray light from surfaces.

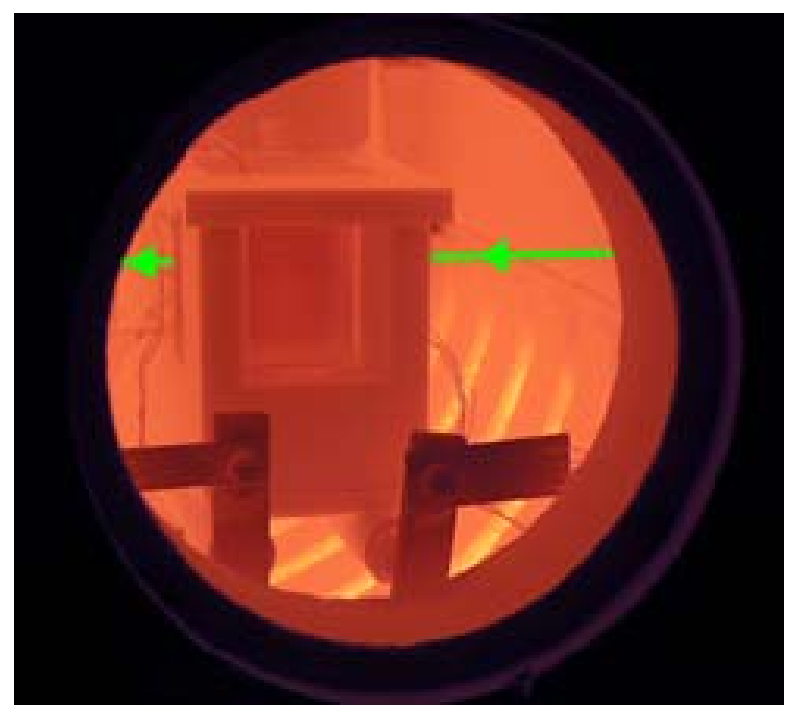

Figure 3. Photograph of the SOFC cell compartment through the observation window for the detection of the Raman scattered radiation. The furnace is at $\mathrm{T} \approx 1123 \mathrm{~K}$. The central part is the transparent flow field consisting of quartz glass and surrounded by ceramic parts. The line indicates the laser beam. 


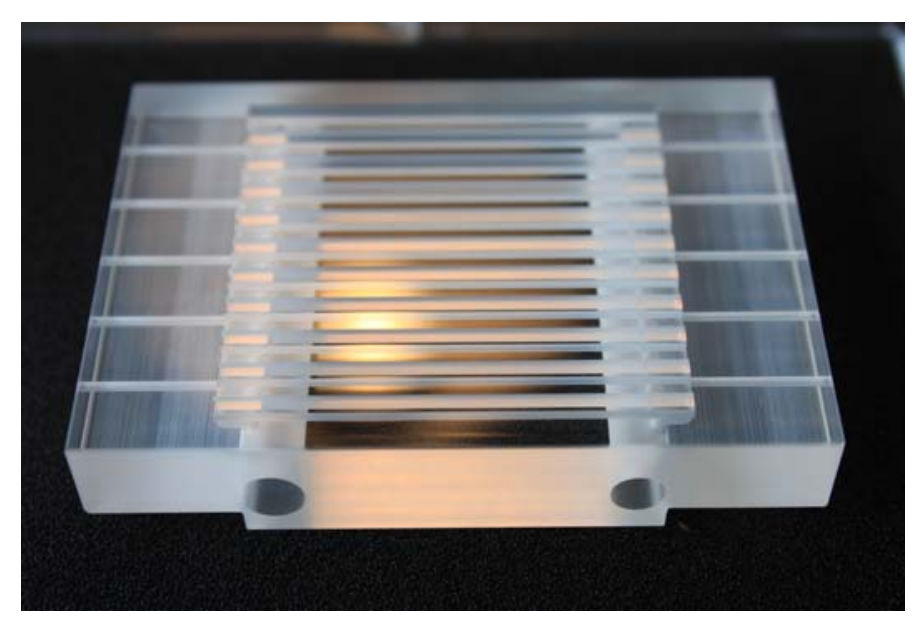

Figure 4. Transparent anode flow field consisting of quartz glass with 9 gas channels $\left(3 \times 4 \mathrm{~mm}^{2}\right)$

\section{Laser Raman Setup}

The optical setup is shown schematically in Fig. 5. The laser system consisted of three double-pulse Nd:YAG lasers (Spectra-Physics PIV 400), which generated a beam consisting of six frequency-doubled pulses $(\lambda=532 \mathrm{~nm})$. After passing through a pulse stretcher, the combined pulse had a duration of $\tau \approx 350 \mathrm{~ns}$ and a pulse energy of $\mathrm{E}_{\mathrm{p}} \approx 1.2 \mathrm{~J}$. This laser system is usually employed for Raman measurements in flames and is described in more detail in the literature $(15,16)$. The laser beam had to be shaped to pass through the $40 \mathrm{~mm}$ long anode gas channel, cross section $3 \times 4 \mathrm{~mm}^{2}$, of the SOFC without damaging the transparent flow field section and without generating considerable amounts of stray light or luminescent emissions in the quartz glass. Therefore, the laser beam was focused by a spherical lens $(f=3 \mathrm{~m})$ in a way that the beam had a waist of approximately $2 \mathrm{~mm}$ in the transparent flow field. To avoid damage of the flow field section, the laser pulse energy was reduced to $\mathrm{E}_{\mathrm{p}} \approx 0.1 \mathrm{~J}$ by means of a combination of a $\lambda / 2$ wave plate and a Glan polarizer (see Fig. 5). The laser pulse energy was monitored in front of and behind the furnace. This enabled a control of the alignment and transmission of the setup and a good estimation of the laser energy in the channel of the flow field.

The scattered light from the laser beam was collected at $90^{\circ}$ by an achromatic lens (f $=160 \mathrm{~mm}$ ) and relayed to the entrance slit of a spectrograph (Acton Research SpectraPro 300i, $f=300 \mathrm{~mm}, 490$ lines $/ \mathrm{mm}, \mathrm{f} / 4$, dispersion $\sim 6 \mathrm{~nm} / \mathrm{mm}$ ). The magnification of the detection optics was 0.4 . The entrance slit had a length of $14 \mathrm{~mm}$ and the width was set to $0.5 \mathrm{~mm}$. The spectrally dispersed image of the light distribution in the entrance slit was captured by an intensified CCD camera (Princeton Instruments PI-Max, $1340 \times 1300$ pixels, $26.8 \mathrm{~mm} \times 26 \mathrm{~mm}$ chip size) equipped with a fiber-coupled image intensifier (Gen III, GaAs photocathode). The raw data acquired by the 1D Raman system consisted of image files with a spatial resolution in the vertical and a spectral resolution in the horizontal direction. The imaged volume had a length of $35 \mathrm{~mm}$ and was divided by pixel binning into 35 superpixels in the spatial direction, corresponding to 35 measurement volumes each with a length of $1 \mathrm{~mm}$ and diameter of $\sim 2 \mathrm{~mm}$ (according to the diameter of the laser beam in the observed section). The 35 spectra from these volumes were recorded simultaneously. In the spectral dimension, five adjacent pixels were binned to 268 superpixels with a spectral resolution of about $0.6 \mathrm{~nm}$. 


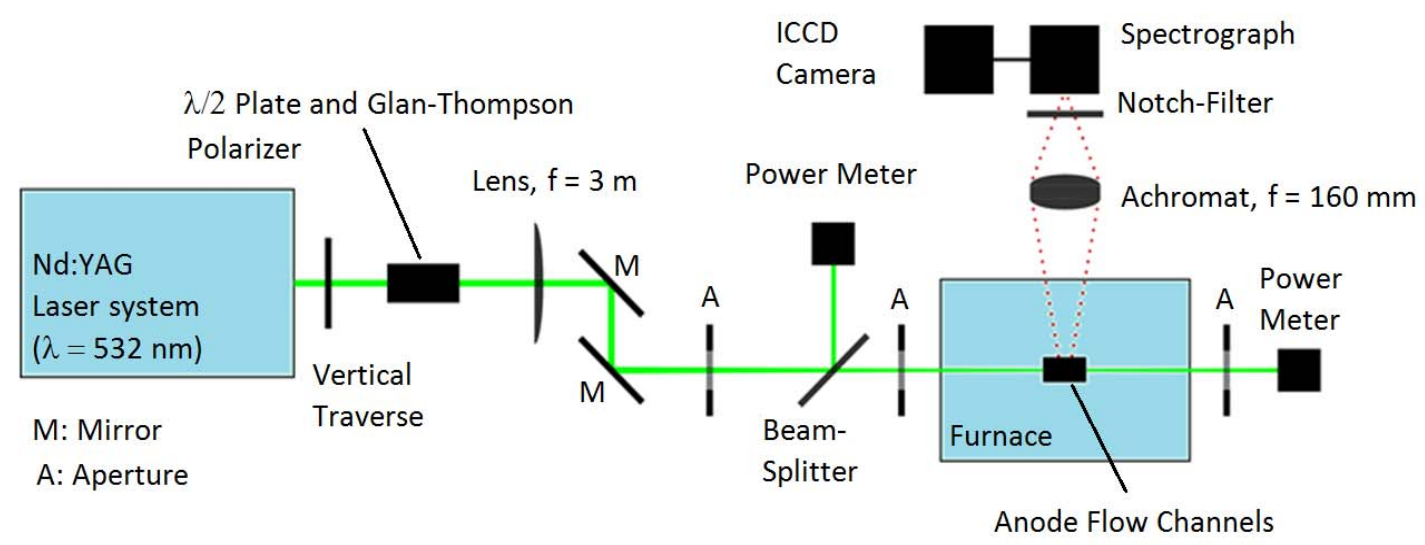

Figure 5. Schematic of the optical setup

\section{Results and Discussion}

Operation of a solid oxide fuel cell requires a specific start-up protocol which was chosen as follows. A fresh SOFC was heated to approximately $1123 \mathrm{~K}$ under supply of 0.25 standard liter per minute (slpm) of forming gas $\left(5 \% \mathrm{H}_{2}\right.$ in $\left.\mathrm{N}_{2}\right)$ to the anode and 0.25 slpm of air to the cathode. After the cell was heated up to the target temperature the anode was reduced, that is, nickel oxide $(\mathrm{NiO})$ present in the anode after cell manufacturing was converted to $\mathrm{Ni}$, the active electrocatalyst. This was achieved by gradually increasing the fuel flow of hydrogen to the anode to $1.25 \mathrm{slpm}$ and the air flow to the cathode to 1.25 slpm. The forming gas was reduced to $0 \mathrm{slpm}$. The reduction process lasted about $1 \mathrm{~h}$ and yielded an open circuit voltage (OCV) of 1.209 V. Subsequently, a polarization curve was recorded by increasing the current load on the cell until the cell voltage reached a lower limit of $0.6 \mathrm{~V}$. The results are shown in Fig. 6 . At a voltage of $0.7 \mathrm{~V}$ the power density of the cell reached $340 \mathrm{~mW} / \mathrm{cm}^{2}$. For this cell type the value is quite high indicating that the cell setup was gas-tight. At a lower fuel gas flow of $0.112 \mathrm{slpm}$ the cell still produced a power density of $219 \mathrm{~mW} / \mathrm{cm}^{2}$.

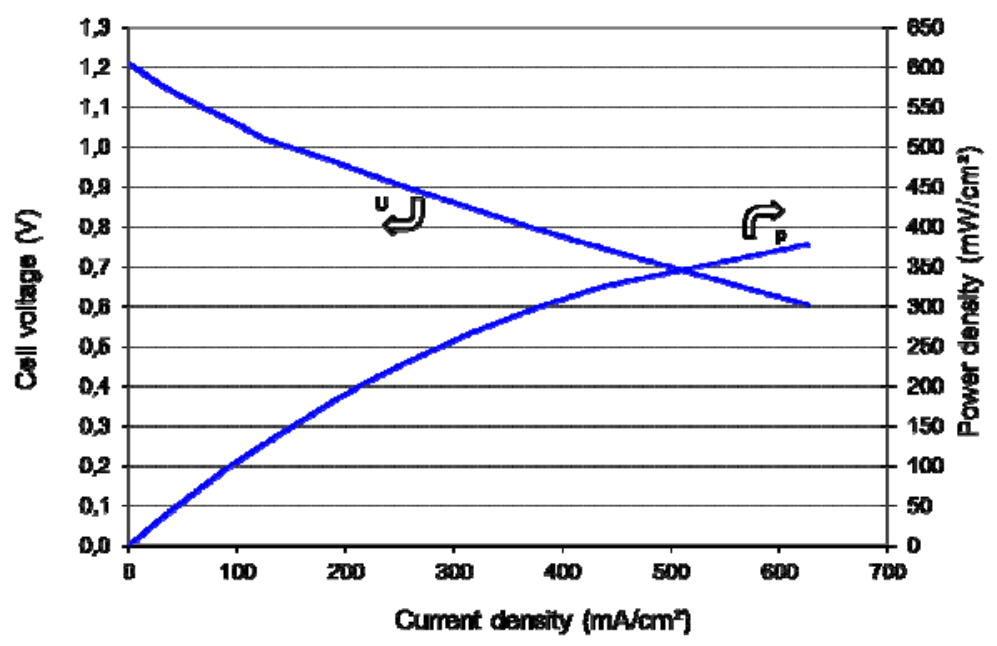

Figure 6. Polarization curve of solid oxide fuel cell $\left(16 \mathrm{~cm}^{2}\right.$ active cell area) operated at $1123 \mathrm{~K}$ 
The system was kept at high temperature for the period of the measurements of 15 days. The ceramic parts of the furnace were red hot at this temperature and excluded a close inspection of the quartz cell by eye (see Figure 3). During the course of the measurement period, the optical transmission of the transparent part of the cell housing and also that of the observation window of the furnace degraded due to a greyish deposit whose origin could not unambiguously be identified. The corresponding reduction in transmission reduced the signal intensity and was taken into account in the data reduction routine.

In-situ Raman laser diagnostics was carried out during SOFC operation under a range of different conditions. Here we present exemplary results for $1123 \mathrm{~K}$, dry $\mathrm{H}_{2}$ as anode gas $(1.25 \mathrm{slpm})$ and air at the cathode $(1.25 \mathrm{slpm})$ for different currents between 0 and $7 \mathrm{~A}$ (corresponding to current densities of $0-437.5 \mathrm{~mA} / \mathrm{cm}^{2}$ ). For each operating point, the Raman signals from 3000 laser shots were accumulated on-chip (corresponding to about 5 minutes measuring time) and corrected for background, vignetting, varying detection efficiency and laser pulse energy. Fig. 7 shows Raman spectra recorded at 312.5 $\mathrm{mA} / \mathrm{cm}^{2}$. The 35 spectra cover a length of $35 \mathrm{~mm}$ along the channel. The $\mathrm{H}_{2} \mathrm{O}$ Raman band appears at $\lambda \approx 660 \mathrm{~nm}$ and the $\mathrm{H}_{2}$ Raman band at $\lambda \approx 683 \mathrm{~nm}$. The $\mathrm{H}_{2}$ signal decreases along the fuel flow direction (from back to front in the figure) while the $\mathrm{H}_{2} \mathrm{O}$ signal increases. Thus, the anodic fuel cell reaction,

$$
\mathrm{H}_{2}+\mathrm{O}^{2-} \rightleftarrows \mathrm{H}_{2} \mathrm{O}+2 \mathrm{e}^{-}
$$

could be successfully monitored in situ with high spatial resolution $(1 \mathrm{~mm})$ at realistic operating conditions. Gas-phase concentrations are proportional to the area under the Raman signals. Therefore, relative concentrations were determined from the Raman spectra shown in Fig. 7.

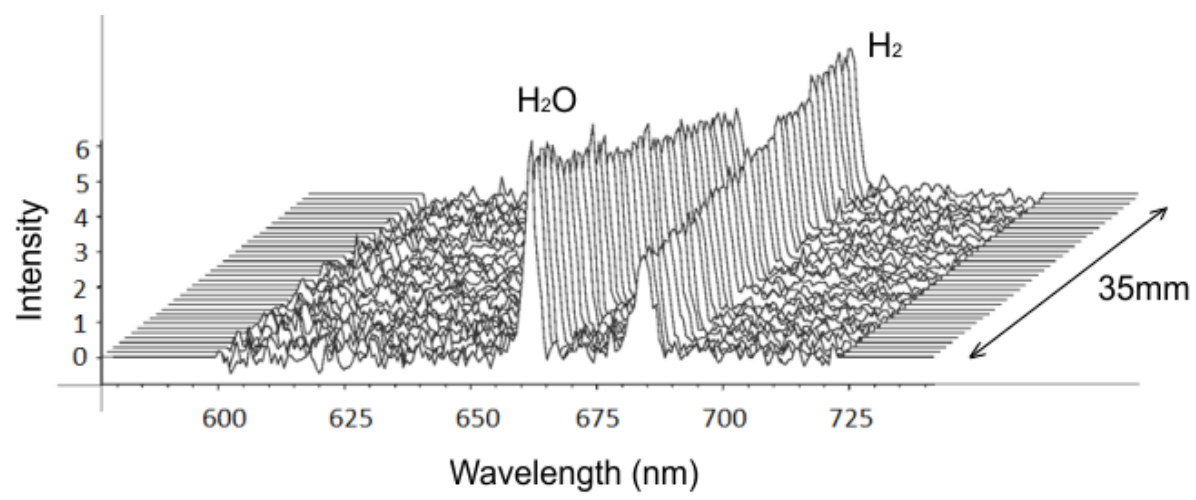

Figure 7. Raman spectra recorded during operation of the SOFC with hydrogen. The 35 spectra cover a length of $35 \mathrm{~mm}$ and have been averaged over 3000 laser shots. The $\mathrm{H}_{2} \mathrm{O}$ Raman band appears at $\lambda \approx 660 \mathrm{~nm}$ and the $\mathrm{H}_{2}$ Raman band at $\lambda \approx 683 \mathrm{~nm}$.

Resulting concentration profiles along the length of the channel are shown in Fig. 8 for various current densities. At open circuit voltage $(\mathrm{OCV})$ without any electrochemical reaction the relative concentrations of $\mathrm{H}_{2}$ and $\mathrm{H}_{2} \mathrm{O}$ are constant along the flow channel. 
The apparent slight decrease of the $\mathrm{H}_{2}$ profile is most likely due to uncertainties related to the signal correction procedure. Under load (1-7 A) the hydrogen concentrations decrease and the steam concentrations increase along the channel length as is expected with ongoing electrochemical reactions. The quality of the Raman signals is sufficient for a quantitative data analysis.
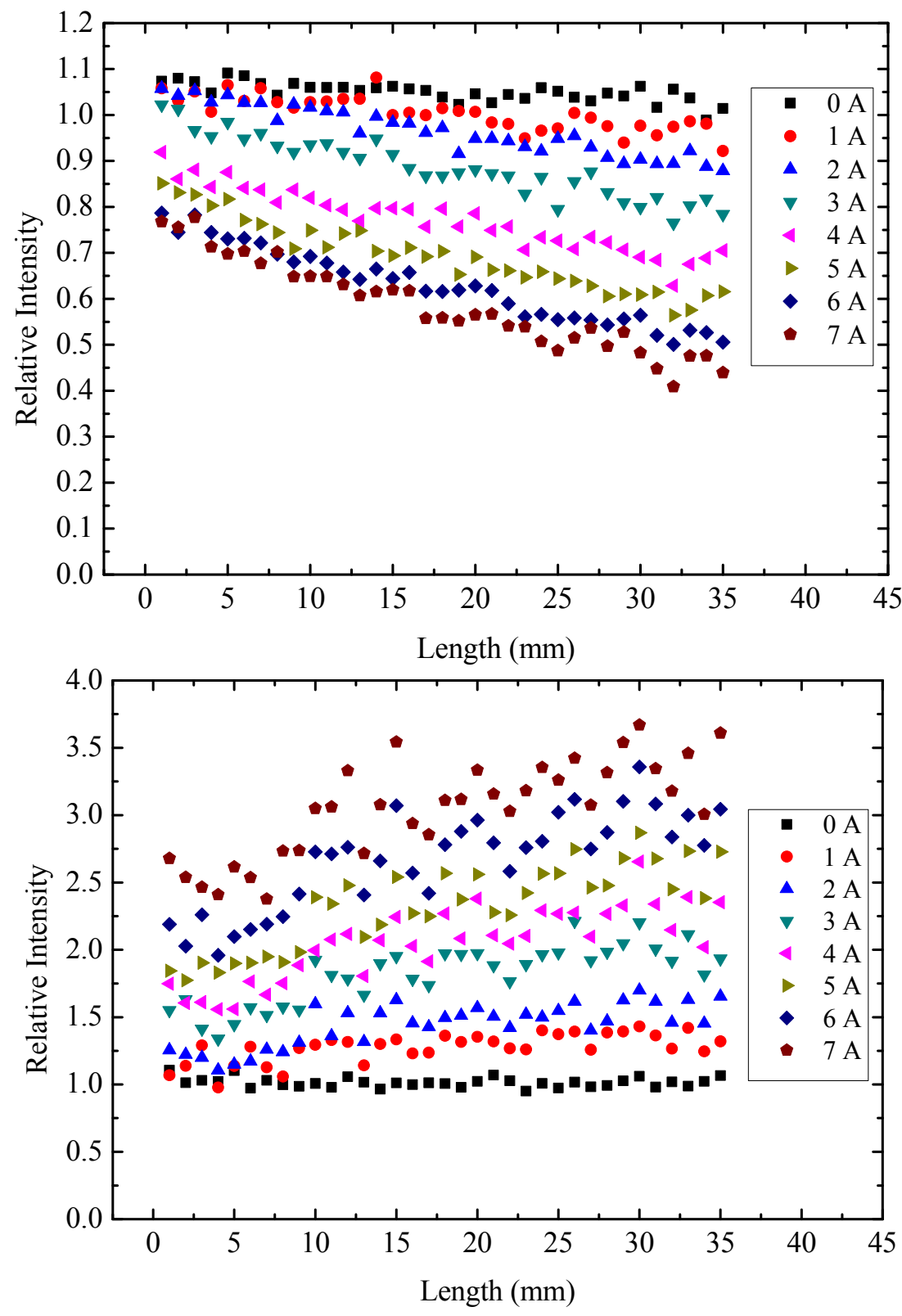

Figure 8. In-situ measurements of $\mathrm{H}_{2}$ (upper diagram) and $\mathrm{H}_{2} \mathrm{O}$ (lower diagram) concentrations along the anode flow channel during operation of the SOFC at $1123 \mathrm{~K}$ at different cell currents.

However, during the measurement period a leakage in the sealing of the cell appeared which was noticed through the appearance of $\mathrm{N}_{2}$ signals in the Raman spectra. This leakage resulted in the uncontrolled chemical oxidation of hydrogen to steam even at 
OCV conditions so that a quantitative evaluation of the obtained Raman signals was no longer possible.

With respect to the Raman measurements, the optical arrangement with the laser beam passing through the channel and signal detection at $90^{\circ}$ enabled the observation of the concentration profiles along the channel without moving parts of the setup to change the measurement location. The difficulties related to this setup are the generation of a long narrow laser beam waist and the avoidance of an optical breakdown and/or damage of the transparent flow by too high laser fluence. In the current setup, the laser pulse energy was reduced to $0.1 \mathrm{~J}$ in order to be clearly below the damage threshold. This corresponds to an average laser power of approximately $286 \mathrm{~kW}$ over the $350 \mathrm{~ns}$ long pulse duration which is still orders of magnitude larger than the power of $\mathrm{CW}$ lasers. A further stretching of the laser pulse would allow to couple more laser pulse energy into the cell and to increase the signal level. It is noted that the pulse duration of a "standard" flashlamp-pumped Nd:YAG is in the order of $10 \mathrm{~ns}$. Applying a similar laser power from such a laser, the pulse energy must be reduced to $\mathrm{E}_{\mathrm{p}} \approx 0.003 \mathrm{~J}$ which is certainly too low for Raman spectroscopy in this application. Care must also be taken to avoid significant generation of laser-induced luminescence from the quartz glass. Due to the small cross section of the channel and the inhomogeneous laser beam profile, exposure of the channel walls to the laser radiation cannot be completely avoided. The analysis of the luminescence signal showed that the problems are less pronounced at elevated temperatures compared to room temperature, but that they might require a more comprehensive background correction for the detection of the $\mathrm{CO}_{2}$ Raman band. Aside from this difficulty, the Raman scattering technique can also be applied using fuels other than hydrogen in this configuration, e.g. methane. In that case, the calibration would include $\mathrm{CH}_{4}, \mathrm{CO}$, and $\mathrm{CO}_{2}$ passing through the channel with the fuel cell at open cell voltage.

In the current setup the signal-to-noise ratio was sufficient for quantitative measurements. However, due to the leakage through a crevice in the assembled cell the results presented here could not be given in mole fractions. At this stage, single shot Raman measurements are hardly quantifiable because they do not yield sufficient signalto-noise ratio. However, the temporal changes within the SOFC are slow enabling an accumulation of Raman signals over several minutes. Also, a spatial resolution of $1 \mathrm{~mm}$ as applied here seems unnecessary and a further binning of pixels would lead to a better signal quality.

Quantitative results of gas concentration measurement by in situ Raman spectroscopy within an operating SOFC can only be achieved when the cell is properly sealed against the surrounding gas atmosphere. This sealing represents a major challenge in the SOFC setup used. A proper sealing which is realized by gold rings, however, requires sufficient pressure which can only be applied in horizontal direction in the cell setup used. This means that all parts must ideally fit during the cell assembly process. In order to assure improved sealing conditions, constructional modifications of the cell compartment and a modified sealing are under development for the future investigations. When achieving a properly operating SOFC, Raman measurements will be performed by applying various operating conditions including complex fuel gas compositions, such as different reformate compositions, and temperature and flow rate variations. The obtained data will be particularly useful for validating detailed models of reforming and fuel cell processes using a physically-based modelling framework (17). 


\section{Summary and Conclusions}

A novel experimental approach was presented for the analysis of chemical species conversion within a solid oxide fuel cell (SOFC) flow channel, based on gas-phase laser diagnostics. The setup enabled the detection of the species concentration profiles along a line of $35 \mathrm{~mm}$ length within the $40 \mathrm{~mm}$ long flow channel. The concentration profiles of $\mathrm{H}_{2}$ and $\mathrm{H}_{2} \mathrm{O}$ were recorded with a spatial resolution of $1 \mathrm{~mm}$ along the channel length and exhibited clearly the expected behavior, i.e. a decrease of $\mathrm{H}_{2}$ and increase of $\mathrm{H}_{2} \mathrm{O}$ concentration along the flow direction. However, due to a leakage of the cell the concentrations could not be quantified. In the next step, an improved cell setup will be used to perform quantitative species measurements at various operating conditions. As Raman scattering allows the simultaneous detection and distinction of different gas-phase species, this technique will be particularly useful for investigating internal reforming conditions where $\mathrm{CH}_{4}, \mathrm{H}_{2}, \mathrm{H}_{2} \mathrm{O}, \mathrm{CO}, \mathrm{CO}_{2}$ and $\mathrm{N}_{2}$ are present simultaneously.

\section{References}

1. P. Metzger, K.A. Friedrich, H. Müller-Steinhagen and G. Schiller, Solid State Ionics, 177, 2045 (2006).

2. P. Metzger, Ortsaufgelöste Charakterisierung von Festelektrolyt-Brennstoffzellen (SOFC) durch Messung betriebsrelevanter Größen entlang des Strömungswegs, PhD Thesis, University Stuttgart, German (2010).

3. G. Schiller, W. Bessler, K.A. Friedrich S. Gewies and C. Willich, ECS Trans., 17(1),79 (2009).

4. P. Metzger, K.A. Friedrich G. Schiller and C. Willich, J. Fuel Cell Sci. Technol. 6(2), 021304-1 (2009).

5. W.G. Bessler, S. Gewies, C. Willich, G. Schiller and K.A. Friedrich, Fuel Cells, 10 (3), $411(2010)$.

6. A.C. Eckbreth, in Laser Diagnostics for Combustion Temperature and Species, p. 1-33, Gordon \& Breach, The Netherlands (1996).

7. R.C. Maher, L.F. Cohen, P. Lohsoontorn, D.J.L. Brett and N.P. Brandon, J. Phys. Chem., A 112, 1497 (2008).

8. M.P. Pomfret, J.C. Owrutsky and R.A. Walker, J. Phys. Chem. B, 110 (35), 17305 (2006).

9. M.P. Pomfret, J.C. Owrutsky and R.A. Walker, Anal. Chem. 79(6), 2367 (2007).

10. Z. Cheng and M. Liu, Solid State Ionics, 178(13-14), 925 (2007).

11. A.J. McGettrick, W. Johnstone, R. Cunningham, and J.D. Black, J. Lightwave Technol., 27(15), 3150 (2009).

12. B.C. Eigenbrodt, J.D. Kirtley and R.A. Walker, ECS Trans., 35(1), 2789 (2011).

13. E. Brightman, R. Maher, D.G. Ivey, G. Offer, and N. Brandon, ECS Trans., 35(1), 1407 (2011).

14. J.E.A. Saunders and M.H. Davy, Int. J. Hydrogen Energy, 37, 3403 (2012).

15. H. Ax, P. Kutne, W. Meier, K. König, U. Maas, A. Class and M. Aigner, Appl. Physics B, 94, 705 (2009).

16. U. Stopper, M. Aigner, H. Ax, W. Meier, R. Sadanandan, M. Stöhr and A. Bonaldo, Exp. Thermal Fluid Sci., 34, 396 (2010).

17. W.G. Bessler, S. Gewies and M. Vogler, Electrochimica Acta, 53, 1782 (2007). 